\title{
Correction
}

\section{Correction: Diffusion Boundary Layers Ameliorate the Negative Effects of Ocean Acidification on the Temperate Coralline Macroalga Arthrocardia corymbosa}

\section{The PLOS ONE Staff}

There are errors in the author affiliations. The affiliations should appear as shown here:

Christopher E. Cornwall ${ }^{1}$, Philip W. Boyd ${ }^{2}$, Christina M. McGraw $^{3,4}$, Christopher D. Hepburn ${ }^{7}$, Conrad A. Pilditch ${ }^{5}$, Jaz N. Morris ${ }^{1}$, Abigail M. Smith ${ }^{7}$, Catriona L. Hurd ${ }^{1,6}$

1 Department of Botany, University of Otago, Dunedin, New Zealand, 2 National Institute for Water and Atmospheric research (NIWA) Centre of Physical and Chemical Oceanography, Dunedin, New Zealand, 3 School of Chemistry and Biochemistry, Clark University, Worcester, Massachusetts, United States of America, 4 School of Science and Technology, University of New England, Armidale, Australia, 5 Department of Biological Sciences, University of Waikato, Hamilton, New Zealand, 6 Institute for Marine and Antarctic Studies, University of Tasmania, Hobart, Tasmania, Australia, 7 Department of Marine Sciences, University of Otago, Dunedin, New Zealand

\section{Reference}

1. Cornwall CE, Boyd PW, McGraw CM, Hepburn CD, Pilditch CA, et al. (2014) Diffusion Boundary Layers Ameliorate the Negative Effects of Ocean Acidification on the Temperate Coralline Macroalga Arthrocardia corymbosa. PLoS ONE 9(5): e97235. doi:10.1371/journal.pone.0097235
Citation: The PLOS ONE Staff (2014) Correction: Diffusion Boundary Layers Ameliorate the Negative Effects of Ocean Acidification on the Temperate Coralline Macroalga Arthrocardia corymbosa. PLoS ONE 9(9): e109468. doi:10.1371/journal. pone.0109468

Published September 26, 2014

Copyright: () 2014 The PLOS ONE Staff. This is an open-access article distributed under the terms of the Creative Commons Attribution License, which permits unrestricted use, distribution, and reproduction in any medium, provided the original author and source are credited. 